\title{
SIMULATION ON THE COMPLEMENTARY PRODUCT STRATEGY BASED ON THE COURNOT-BERTRAND MIXED GAME MODEL
}

\author{
Huang, Y.-M.; Liu, L.* \& Qi, E.-S. \\ College of Management and Economics, Tianjin University, Tianjin 300072, China \\ E-Mail: liuliang@tju.edu.cn ("Corresponding author)
}

\begin{abstract}
In this article, we report the results of a study that explores an output-pricing game model in a complex system which comprises two main manufacturers and two complementary product enterprises. First, optimization method is used to study the influence of parameters on the optimal decisions of the model. Second, a dynamic game model and a controlled model are established in order to analyse the system's dynamic characteristics in disequilibrium state by dynamic simulation. The simulation results show that the increase of product substitutability will be unfavourable to all members of the complex system, enterprises should control the product's complementarity thus can they obtain maximum profit respectively. In addition, enterprises in the system can reach Nash Equilibrium, but complementary enterprises are lack of cooperation enthusiasm with the increase of substitutability of main product. The complex characteristics of the model with the change of parameters is exhibited by dynamic simulation, and the stability of variables will change when the parameters taking different values. The results can provide references for managers in variable adjustment, choice of complementary product strategy and product design, etc.

(Received, processed and accepted by the Chinese Representative Office.)
\end{abstract}

Key Words: Complementary Product, Cournot-Bertrand Mixed Model, Dynamic Simulation, Chaos

\section{INTRODUCTION}

Because the market economics in China has become increasingly complex, ambiguous, and pluralistic, the competition between manufacturers is fiercely increasing. Some enterprises have achieved the purpose of expanding demand and increasing profit through service extension strategy [1,2]. Under the lean production mode, if enterprises want to achieve profit growth without increasing investment, they have to change the production mode and fully integrate all resources. In practice, delay decisions can make enterprises more accurately grasp the market information, reduce the uncertainty of demand, production and inventory, weak bullwhip effect in certain degree, and make decision-making more close to or reach the optimal state. But these enterprises are competing with each other under the original market size, unable to make full use of external resources to create customer's demand.

In the complex environment, the competition between enterprises is not limited within the industry, and most of the products are affected by complementary products to a certain extent, and therefore, more and more enterprises want to expand business in the industry external. As a result it appears to be particularly important to study how to expand the market size through the development of complementary product or make existing complementary product more popular. However, the study on independent decision of variables and the stability between competitive manufacturers and complementary enterprises is very rare in the existing literature, and this paper is going to fill the gap.

In this paper, we first develop a Cournot-Bertrand mixed game model based on systematic analysis and dynamic analysis of complementary product development in which two main manufacturers $\left(M_{1}\right.$ and $\left.M_{2}\right)$ choose the two common complementary enterprises $\left(M_{3}\right.$ and $\left.M_{4}\right)$, the complementary enterprises give priority to adjust the prices and the main manufacturers give priority to adjust the outputs to maximize their profits, they carry out 
mixed Cournot-Bertrand game, and the influence of parameter changes on stability of the system is analysed and its controlled model is developed (see Fig. 1).

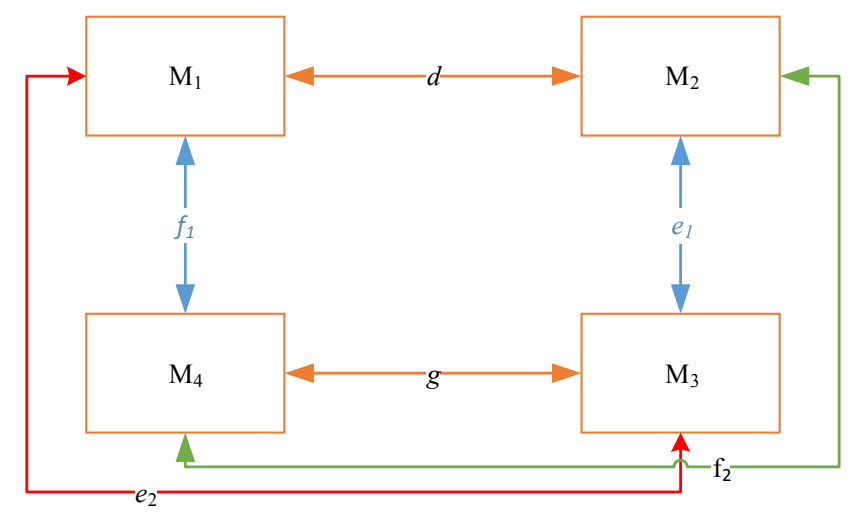

Figure 1: The bilateral cooperative complementary product strategy.

The remainder of this paper is organized as follows: In section 2, we introduced the related literature review and emphasized our contribution to the work. In section 3, we described the problem assumptions and constructed a Cournot-Bertrand Mixed Game of the system, numerical simulations were performed. We constructed dynamic evolution game model of the system and analysed its stability in section 4. Section 5 constructed a chaos control model. Finally, we summarized the paper, discussed some restrictive assumptions, and suggested research extension in section 6 .

\section{LITERATURE REVIEW}

A considerable amount of research has been carried out on the problem related to the optimal pricing decision of a single product or substitutable products [3-9]. On the contrary, the concept of complementary products arises when customers have to buy more than one product at the same time to obtain the full utility of the products [10]. Complementary product strategy has gained interest in recent years, the enterprises supplying products to the market are coupled in the sense and their demands are interrelated [11]. The marketing paradigm of complementary products is different from that of substitutable products in which the enterprises benefit from each other's sales rather than losing sales of the other firm [10]. For example, HP leads the world in laser printers; Canon, on the other hand, supplies components to the same market [12]. The pricing of one product plays an important role in output and customer demand of the other product.

At present, many literatures have studied the bundling price of complementary products between manufacturers and retailers. In this context, the degree of complementarity will influence the advantages of bundled products, and the optimum bundling makes the enterprises maximize their profit. According to Cournot [13], if joint consumption is mandatory, enterprises should set a price based on the value of the joint consumption. In [14], they confirmed Cournot's view by showing that a firm could charge higher prices by selling complementary products to customers who prefer the composite goods. In [10], they presented a profit maximization model to obtain optimal pricing strategies. [15] developed a profit-maximization model which could help firms find optimum bundled product categories and pricing strategies, and found that optimum bundle price strategies existed. [16] also used a profit-maximization model to investigate the strategic influence of product complementarity and advertising on the success of bundle products, found that advertising played a positive role for the bundling strategy. [17] proposed complementary products model on price 
competition between manufacturers and retailers, if one is priced high, the other will be discounted, bundling practices are shown to be detrimental to retailers' profits.

Above literatures were mainly researched on bundle sales of complementary products in a supply chain including the manufacturers and the retailers, ignoring independent decision of variables between the manufacturers and complementary enterprises under the condition of without bundle sales.

The mixed output-pricing game in oligopolistic market has been dealt by many scholars. For instance, in competitive market, one enterprise competes in a dominant position and chooses output as decision variable while the other one is in disadvantage and chooses price as decision variable [18]. As far as we have known, Bylka et al and Singh et al were the first to analyse the mixed Cournot-Bertrand game [19, 20]. Häckner, Zanchettin and Arya et al. pointed that in some cases Cournot-Bertrand competition may be optimal [21-23]. [24] studied a Cournot-Bertrand mixed duopoly competitive game model with limited information about the market.

Few researchers have considered the output-pricing decisions of complementary products. [25] considered a duopoly industry providing two complementary products and analysed the price equilibriums in this market with reference to the degree of complementarity existing between the two products. [26] studied the Bertrand model for complementary products with firms' different market powers. These studies only considered the Bertrand game of a single complementary product, and in this paper we will study the mixed Cournot-Bertrand game models where the two main manufacturers choose output as decision variable while the two complementary enterprises choose price as decision variable.

\section{THE COURNOT-BERTRAND GAME MODEL}

\subsection{Assumptions}

(i) The system comprises of two main manufacturers $\left(M_{1}\right.$ and $\left.M_{2}\right)$ and two complementary product enterprises $\left(M_{3}\right.$ and $\left.M_{4}\right) ; M_{1}$ and $M_{2}$ produce two differentiated products (product 1 and product 2) and optimally take output as control variable; $M_{3}$ and $M_{4}$ produce two complementary products (product 3 and product 4 ) for $M_{1}$ and $M_{2}$, and take prices as control variable.

(ii) The demand for products in the market is always satisfied, and the participants are all risk neutral and maximize their profits respectively.

(iii) The participants make decision simultaneously and do not regard the reaction of the other.

\subsection{Notations}

Notations used in this paper are listed in Table I.

Table I: Notations in the complex system.

\begin{tabular}{|clll|}
\hline$M_{i}, i=1,2$ & Main manufacturer & $b$ & The possible largest demand of product 3 \\
$M_{j}, j=3,4$ & Complementary enterprise & $h$ & The possible largest demand of product 4 \\
$q_{i}, i=1,2$ & Output of main manufacturer & $d$ & Substitution between product 1 and product 2 \\
$p_{j}, j=3,4$ & Price of complements & $\mathrm{g}$ & Substitution between product 3 and product 4 \\
$\pi_{i}, i=1,2,3,4$ & Profit of each participant & $e_{1}$ & Complementarity between product 2 and product 3 \\
$c_{i}, i=1,2,3,4$ & Cost of each enterprise & $e_{2}$ & Complementarity between product 1 and product 3 \\
$a$ & The possible largest demand of product & $f_{1}$ & Complementarity between product 1 and product 4 \\
& 1 and product 2 & $f_{2}$ & Complementarity between product 2 and product 4 \\
\hline
\end{tabular}




\subsection{Peer-to-peer game model}

We consider that the relationship between industries is co-operative rather than cutthroat in competition, the complicated relations between two main manufacturers and two complementary enterprises are considered (see Fig. 1), we assume the inverse demand functions are as follows [27]:

$$
\begin{aligned}
& p_{1}=a-q_{1}-d q_{2}+f_{1} q_{4}+e_{2} q_{3} \\
& p_{2}=a-q_{2}-d q_{1}+e_{1} q_{3}+f_{2} q_{4} \\
& p_{3}=a-q_{3}-g q_{4}+e_{1} q_{2}+e_{2} q_{1} \\
& p_{4}=h-q_{4}-g q_{3}+f_{1} q_{1}+f_{2} q_{2}
\end{aligned}
$$

where $d>0, g>0, e_{i}>0, f_{i}>0, i=1,2$ and satisfies $a>c_{1}, a>c_{2}, b>c_{3}, h>c_{4}$.

So, the demand system in the two strategic variables (price and quantity) can be described:

$$
\begin{aligned}
& p_{1}=a-q_{1}-d q_{2}+\frac{f_{1}\left[h-b g+g p_{3}-p_{4}+\left(f_{1}-e_{2} g\right) q_{2}\right]}{1-g^{2}}+\frac{e_{2}\left[b-h g+g p_{4}-p_{3}+\left(e_{2}-f_{1} g\right) q_{1}+\left(e_{1}-f_{2} g\right) q_{2}\right]}{1-g^{2}} \\
& p_{2}=a-q_{2}-d q_{1}+\frac{f_{2}\left[h-b g+g p_{3}-p_{4}+\left(f_{1}-e_{2} g\right) q_{2}\right]}{1-g^{2}}+\frac{e_{1}\left[b-h g+g p_{4}-p_{3}+\left(e_{2}-f_{1} g\right) q_{1}+\left(e_{1}-f_{2} g\right) q_{2}\right]}{1-g^{2}} \\
& q_{3}=b-p_{3}+e_{1} q_{2}+e_{2} q_{1}-\frac{g\left[h-b g+g p_{3}-p_{4}+\left(f_{1}-e_{2} g\right) q_{2}\right]}{1-g^{2}} \\
& q_{4}=h-p_{4}+f_{1} q_{1}+f_{2} q_{2}-\frac{g\left[b-h g+g p_{4}-p_{3}+\left(e_{2}-f_{1} g\right) q_{1}+\left(e_{1}-f_{2} g\right) q_{2}\right]}{1-g^{2}}
\end{aligned}
$$

The profit functions of four enterprises are in the form:

$$
\begin{aligned}
& \pi_{1}=q_{1} p_{1}-c_{1} q_{1} \\
& \pi_{2}=q_{2} p_{2}-c_{2} q_{2} \\
& \pi_{3}=\left(p_{3}-c_{3}\right) q_{3} \\
& \pi_{4}=\left(p_{4}-c_{4}\right) q_{4}
\end{aligned}
$$

We firstly carry out a qualitative study on the relationship between price strategy and output strategy. The marginal profits of the four manufacturers are as follows:

$$
\begin{gathered}
\frac{\partial \pi_{1}}{\partial q_{1}}=a-q_{1}-d q_{2}-\left(1+\frac{f_{1}\left(f_{1}-e_{2} g\right)}{1-g^{2}}+\frac{e_{2}\left(e_{2}-f_{1} g\right)}{1-g^{2}}\right) q_{1}+ \\
+\frac{f_{1}\left[h-b g+g p_{3}-p_{4}+\left(f_{1}-e_{2} g\right) q_{1}+\left(f_{2}-e_{1} g\right) q_{2}\right]}{1-g^{2}}+\frac{e_{2}\left[b-h g+g p_{4}-p_{3}+\left(e_{2}-f_{1} g\right) q_{1}+\left(e_{1}-f_{2} g\right) q_{2}\right]}{1-g^{2}} \\
\frac{\partial \pi_{2}}{\partial q_{1}}=a-q_{2}-d q_{1}-\left(1+\frac{f_{2}\left(f_{2}-e_{1} g\right)}{1-g^{2}}+\frac{e_{1}\left(e_{1}-f_{2} g\right)}{1-g^{2}}\right) q_{2}+ \\
+\frac{f_{2}\left[h-b g+g p_{3}-p_{4}+\left(f_{1}-e_{2} g\right) q_{1}+\left(f_{2}-e_{1} g\right) q_{2}\right]}{1-g^{2}}+\frac{e_{1}\left[b-h g+g p_{4}-p_{3}+\left(e_{2}-f_{1} g\right) q_{1}+\left(e_{1}-f_{2} g\right) q_{2}\right]}{1-g^{2}} \\
\frac{\partial \pi_{3}}{\partial p_{3}}=b-p_{3}+e_{2} q_{1}+e_{1} q_{2}+\left(-1-\frac{g^{2}}{1-g^{2}}\right)-\frac{g\left[h-b g+g p_{3}-p_{4}+\left(f_{1}-e_{2} g\right) q_{1}+\left(f_{2}-e_{1} g\right) q_{2}\right]}{1-g^{2}} \\
\frac{\partial \pi_{4}}{\partial p_{4}}=h-p_{4}+f_{1} q_{1}+f_{2} q_{2}+\left(-1-\frac{g^{2}}{1-g^{2}}\right)\left(-c_{4}+p_{4}\right)- \\
-\frac{g\left[b-h g+g p_{4}-p_{3}+\left(e_{2}-f_{1} g\right) q_{1}+\left(e_{1}-f_{2} g\right) q_{2}\right]}{1-g^{2}}
\end{gathered}
$$

So solving $q_{1}, q_{2}, p_{3}, p_{4}$ from the equations: $\frac{\partial \pi_{1}}{\partial q_{1}}=\frac{\partial \pi_{2}}{\partial q_{2}}=\frac{\partial \pi_{3}}{\partial p_{3}}=\frac{\partial \pi_{4}}{\partial p_{4}}=0$, we can obtain the expression of Nash equilibrium point which is very complex, and the relations between the variables and parameters cannot be observed directly. Then, the influence of parameters on equilibrium variable values and equilibrium profits is studied using numerical simulation. A 
selected set of parameters is given as follows: $a=1, b=1, d=0.2, e_{1}=0.2, e_{2}=0.2, f_{1}=0.2$, $f_{2}=0.2, g=0$, the marginal costs of the four enterprises are $c_{i}, i=1,2,3,4$, satisfying $a>c_{i}$. Next, we simulate the influence of parameter changes on the equilibrium values and profits when $d$ and $g$ takes different values.

(1) The influences with the change of parameter $f_{1}$ on the equilibrium values and profits when $d$ takes different value

Figs. 2 and 3 show the changes of equilibrium values and profits with the increase of $f_{1}$ when $d$ takes a different value. We can obtain (1) the equilibrium values and profits of all participants decrease with the increase of $d$. (2) When $d$ takes different value, the output of $M_{1}$ and the price of $M_{4}$ are increasing in $f_{1}$; The output of $M_{2}$ and the price of $M_{3}$ are decreasing in $f_{1}$. The profit of $M_{1}$ is increasing in $f_{1}$, the profits of $M_{2}, M_{3}$ and $M_{4}$ are increasing first and then decreasing with the change of $f_{1}$. (3) The complementary coefficients which makes the profits of $M_{2}, M_{3}$ and $M_{4}$ maximize decrease with the increase of $d$. Namely, the smaller the degree of differentiation of main products is, the smaller the complementary coefficient which makes the profit of complementary enterprises maximize will be. So, complementary enterprises will control complementary coefficient to maximize their profit. (4) When $d$ takes different value, the profit of $M_{3}$ has always been greater than that of $M_{4}$ with the change of $f_{1}$. Namely, with the increase of the complementary coefficient, the benefit the $M_{3}$ gains is more than that of $M_{4}$ which reduces the cooperative enthusiasm of $M_{1}$ and $M_{4}$.

(2) The influence which the change of parameters $f_{1}$ has on the equilibrium values and profits when $g$ takes different value

Figs. 4 and 5 show the changes of equilibrium value and profit with increase of $f_{1}$ when $d$ takes different value. We can see (1) the equilibrium value and equilibrium profit of all participants are decreasing in $g$. (2) When $g \leq 0.6$, the output of $M_{1}$ and the price of $M_{4}$ are increasing in $f_{1}$, the output of $M_{2}$ and the price of $M_{3}$ are decreasing in $f_{1}$. When $g \geq 0.6$, all variables change significantly and show complex features with the change of $f_{1}$, and the market is very unstable. (3) When $g \leq 0.6$, the profit of $M_{1}$ and $M_{4}$ are increasing in $f_{1}$, and the profit of $M_{2}$ and $M_{3}$ are first increasing and then decreasing with the change of $f_{1}$. When $g \geq 0.6$, the profit of $M_{3}$ is decreasing in $f_{1}$, and the profit of $M_{1}, M_{2}$ and $M_{4}$ are first increasing and then decreasing with the change of $f_{1}, M_{1}$ must control complementary coefficient for maximizing profit. (4) Under different values of $g$, when the profit of $M_{1}$ and $M_{4}$ get maximized value, the profit of $M_{2}$ and $M_{3}$ are less than zero, $M_{2}$ and $M_{3}$ will exit the market. So, in this scenario, the manufacturer can unite complementary enterprise to make the competitors out of business.

\section{THE SIMULATION BASED ON THE COURNOT-BERTRAND GAME}

The Nash Equilibrium state is only short dated and impermanent, some variable factors, such as the price adjustment speed of each participants, the change of substitutability caused by the change of product, the complementarity and so on, can change the market state and keep away from the Nash equilibrium point.

When making decisions, restricted by the objective conditions such as the decision ability and so on, enterprises do not have the perfect market information and they usually make decision based on the partial information in most cases. Suppose that enterprises adjust variables with bounded rationality which based on the marginal utility of the current period. If marginal profit of current period is positive (negative), they will increase (decrease) their output or price in the next period. The variable adjustment affects the enterprises' behaviour. If the variable adjustment is too fast, the enterprise may be far away from equilibrium point and cannot reach the equilibrium state; when the variable adjustment is too slow, the enterprise operates in a sub-health state. 

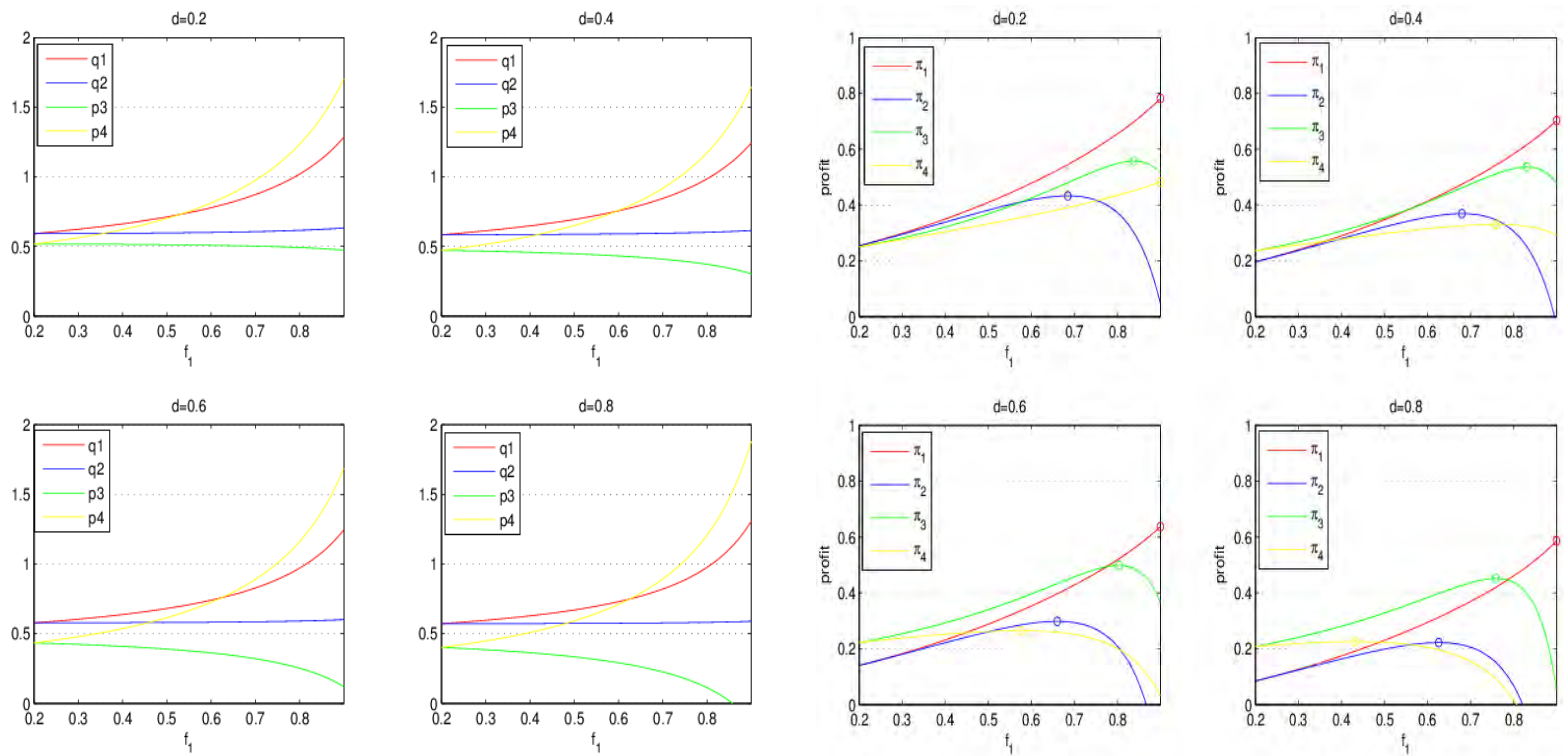

Figure 2: Equilibrium values with the change of $f_{1}$ when $g$ takes different value.

Figure 3: Equilibrium profits with the change of $f_{1}$ when $g$ takes different value.
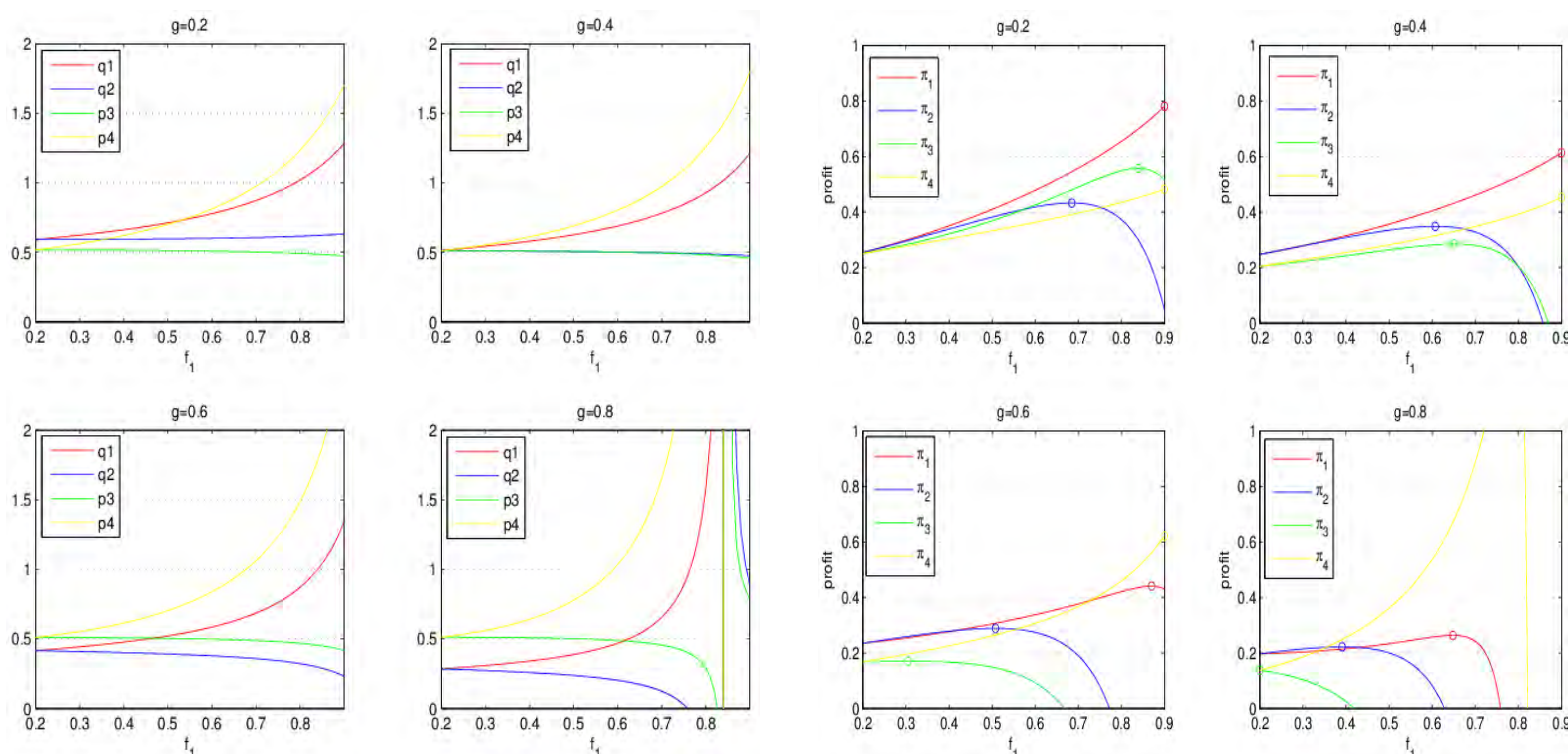

Figure 4: Equilibrium value with the change of $f_{1}$ when $g$ takes different value.
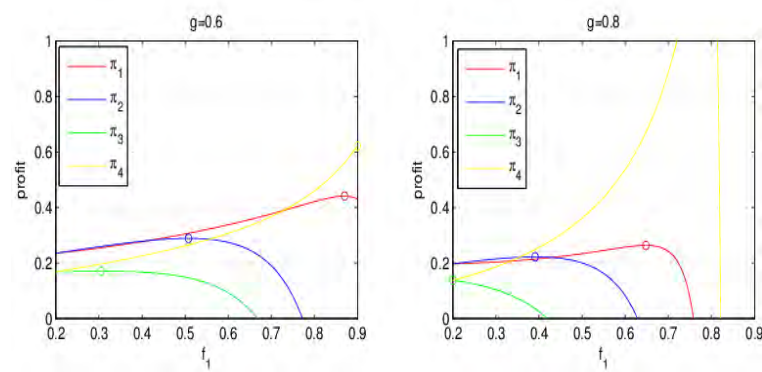

Figure 5: Equilibrium profit with the change of $f_{1}$ when $g$ takes different value.

So it is of great significance in studying the evolution process of the variables from the unbalanced state to equilibrium state. The dynamic Cournot-Bertrand game the system has the following form:

$$
\begin{aligned}
& q_{1}(t+1)=q_{1}(t)+\alpha_{1} q_{1}(t) \frac{\partial \pi_{1}}{\partial q_{1}} \\
& q_{2}(t+1)=q_{2}(t)+\alpha_{2} q_{2}(t) \frac{\partial \pi_{2}}{\partial q_{2}} \\
& p_{3}(t+1)=p_{3}(t)+\alpha_{3} p_{3}(t) \frac{\partial \pi_{3}}{\partial p_{3}} \\
& p_{4}(t+1)=p_{4}(t)+\alpha_{4} p_{4}(t) \frac{\partial \pi_{4}}{\partial p_{4}}
\end{aligned}
$$

where $\alpha_{i},(i=1,2,3,4)$ is a variable adjustment speed parameter. 


\subsection{Equilibrium points}

A selected set of parameters is the same as the above, let $q_{1}(t+1)=q_{1}(t), q_{2}(t+1)=q_{2}(t)$, $p_{3}(t+1)=p_{3}(t), p_{4}(t+1)=p_{4}(t)$, we get four fixed points of the system. They are:

$$
\begin{aligned}
& E_{1}=(0.5,0,0,0.5), E_{2}=(0.55,0,0.5625,0.45), E_{3}=(0.5,0.6433,0,0.47), \\
& E_{4}=(0.5921,0.5921,0.518,0.518) .
\end{aligned}
$$

Obviously, $E_{1}, E_{2}, E_{3}$ are bounded equilibrium points, $E_{4}$ is the only unique Nash equilibrium point.

\subsection{Stability characteristic of Nash equilibrium point}

To study the local stabilities of the Nash equilibrium point, we will calculate the Jacobian matrix of the system at first. It is:

$$
J\left(E_{4}\right)=\left[\begin{array}{cccc}
u_{11} & u_{12} & \frac{\alpha_{1}\left(e_{2}-f_{1} g\right) q_{1}}{-1+g^{2}} & \frac{\alpha_{1}\left(f_{1}-e_{2} g\right) q_{1}}{-1+g^{2}} \\
u_{21} & u_{22} & \frac{\alpha_{2}\left(e_{1}-f_{2} g\right) q_{2}}{-1+g^{2}} & \frac{\alpha_{2}\left(f_{2}-e_{1} g\right) q_{2}}{-1+g^{2}} \\
\frac{\alpha_{3}\left(e_{2}-f_{1} g\right) p_{3}}{-1+g^{2}} & \frac{\alpha_{3}\left(e_{12}-f_{2} g\right) p_{3}}{-1+g^{2}} & u_{33} & \frac{\alpha_{3} g p_{3}}{-1+g^{2}} \\
\frac{\alpha_{4}\left(f_{1}-e_{2} g\right) p_{4}}{-1+g^{2}} & \frac{\alpha_{4}\left(f_{2}-e_{1} g\right) p_{4}}{-1+g^{2}} & \frac{\alpha_{4} g p_{4}}{-1+g^{2}} & u_{44}
\end{array}\right]
$$

where:

$$
\begin{aligned}
u_{11}= & 1+\frac{\alpha_{1}\left(2-2 e_{2}^{2}-2 e f_{1}^{2}+4 e_{2} f_{1} g-2 g^{2}\right) q_{1}}{-1+g^{2}} \\
& +\frac{\alpha_{1}\left(c_{1}-b e_{2}+b f_{1} g-c_{1} g^{2}+a\left(-1+g^{2}\right)-f_{1} h+e_{2} g h-e_{2} p_{3}-f_{1} g p_{3}+f_{1} p_{4}-e_{2} g p_{4}+2 q_{1}\right)}{-1+g^{2}} \\
& +\frac{\alpha_{1}\left(-2 e_{2}^{2} q_{1}-2 f_{1}^{2} q_{1}+4 e_{2} f_{1} g q_{1}-2 g^{2} q_{1}+d q_{2}-e_{1} e_{2} q_{2}-f_{1} f_{2} q_{2}+e_{1} f_{1} g q_{2}+e_{2} f_{2} g q_{2}-d g^{2} q_{2}\right)}{-1+g^{2}} \\
u_{12}= & \frac{\alpha_{1}\left(d-e_{1} e_{2}-f_{1} f_{2}++e_{1} f_{1} g+e_{2} f_{2} g-d g^{2}\right) q_{1}}{-1+g^{2}}, \quad u_{21}=\frac{\alpha_{2}\left(d-e_{1} e_{2}-f_{1} f_{2}++e_{1} f_{1} g+e_{2} f_{2} g-d g^{2}\right) q_{2}}{-1+g^{2}} \\
u_{22}= & 1+\frac{\alpha_{2}\left(2-2 e_{1}^{2}-2 e f_{2}^{2}+4 e_{1} f_{2} g-2 g^{2}\right) q_{2}}{-1+g^{2}} \\
& +\frac{\alpha_{2}\left(c_{2}-b e_{1}+b f_{2} g-c_{2} g^{2}+a\left(-1+g^{2}\right)-f_{2} h+e_{1} g h-e_{1} p_{3}-f_{2} g p_{3}+f_{2} p_{4}-e_{1} g p_{4}+d q_{1}\right)}{-1+g^{2}} \\
& +\frac{\alpha_{2}\left(-2 e_{1}^{2} q_{1}-2 f_{2}^{2} q_{21}+4 e_{1} f_{2} g q_{2}-2 g^{2} q_{2}+2 q_{2}-e_{1} e_{2} q_{1}-f_{1} f_{2} q_{1}+e_{1} f_{1} g q_{1}+e_{2} f_{2} g q_{1}-d g^{2} q_{1}\right)}{-1+g^{2}} \\
u_{33}= & 1-\frac{2 \alpha_{3} p_{3}}{-1+g^{2}}+\frac{\alpha_{3}\left(b+c_{3}-g h-2 p_{3}+g p_{4}+e_{2} q_{1}-f_{1} g q_{1}+e_{1} q_{2}-f_{2} g q_{2}\right)}{-1+g^{2}} \\
u_{44} & =1-\frac{2 \alpha_{4} p_{4}}{-1+g^{2}}+\frac{\alpha_{4}\left(h+c_{4}-b g-2 p_{4}+g p_{3}+f_{1} q_{1}-e_{2} g q_{1}+f_{2} q_{2}-e_{1} g q_{2}\right)}{-1+g^{2}}
\end{aligned}
$$

Then, we put the values of the parameters and the $E_{4}=(0.5921,0.5921,0.518,0.518)$ into $J(E)$, we calculate its characteristic equation:

where:

$$
f(\lambda)=\lambda^{4}+A \lambda^{3}+B \lambda^{2}+C \lambda+D
$$

$$
\begin{aligned}
& A=-3.08+1.23 \alpha_{1}+1.23 \alpha_{2}+0.92 \alpha_{3} \\
& B=3.25-2.25 \alpha_{1}-2.25 \alpha_{2}+1.5 \alpha_{1} \alpha_{2}-1.92 \alpha_{3}+1.13 \alpha_{1} \alpha_{3}+1.13 \alpha_{2} \alpha_{3} \\
& C=-1.25+1.42 \alpha_{1}+1.42 \alpha_{2}-1.61 \alpha_{1} \alpha_{2}+1.09 \alpha_{3}-1.23 \alpha_{1} \alpha_{3}-1.13 \alpha_{2} \alpha_{3}+1.4 \alpha_{1} \alpha_{2} \alpha_{3} \\
& D=0.08-0.09 \alpha_{1}-0.09 \alpha_{2}+0.11 \alpha_{1} \alpha_{2}-0.09 \alpha_{3}+0.1 \alpha_{1} \alpha_{3}+0.1 \alpha_{2} \alpha_{3}-0.11 \alpha_{1} \alpha_{2} \alpha_{3}
\end{aligned}
$$


According to jury conditions [28], the sufficient and necessary conditions that equilibrium point is locally stable are:

$$
\begin{gathered}
1+A+B+C+D>0 \\
1-A+B-C+D>0 \\
\left(1-D^{2}\right)^{2}-(C-A D)^{2}>0 \\
{\left[\left(1-D^{2}\right)^{2}-C-A D^{2}\right]^{2}-\left[B(1-D)^{3}-(A-C D)(C-A D)\right]^{2}>0}
\end{gathered}
$$

Therefore, we can obtain the stability region of the Nash equilibrium point surrounded by $\alpha_{1}, \alpha_{2}, \alpha_{3}$, when $\alpha_{4}=1$ (see Fig. 6). In stability region, regardless of how much the initial outputs and prices are, after a finite time game, the outputs of main manufacturers and the prices of complementary enterprises will be stable in Nash equilibrium point. However, when variable adjustment is beyond the stability region, the system's stability in Nash equilibrium point will be broken, and the phenomena including bifurcation and chaos will appear. Bifurcation and chaos mean that there exists disorderly competition which is harmful to the whole market. Next, we will analyse the influence of parameter changes on the stability of the system.

\subsection{The influence of parameter changes on the stable region of the system}

Fig. 7 is the stability region of the system when $d=0.6$ and $\alpha_{4}=1$, it can be seen that the stability region of output adjustment of the main manufacturer decreases while the stability region of price adjustment of the complementary enterprise increases.

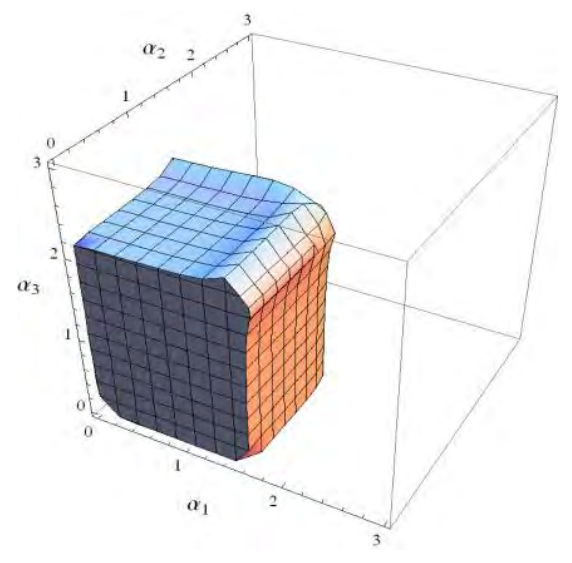

Figure 6: The stability region of the system when $\alpha_{4}=1, d=0.2, f_{1}=0.2, g=0.2$.

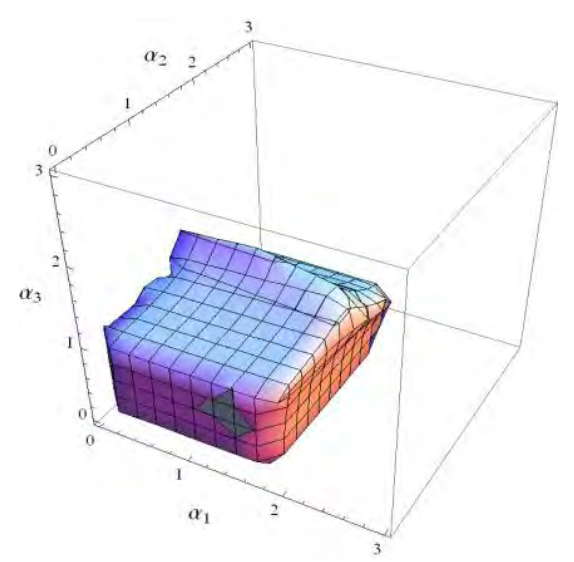

Figure 8: The stability region of the system when $\alpha_{4}=1, d=0.2, f_{1}=0.6, g=0.2$.

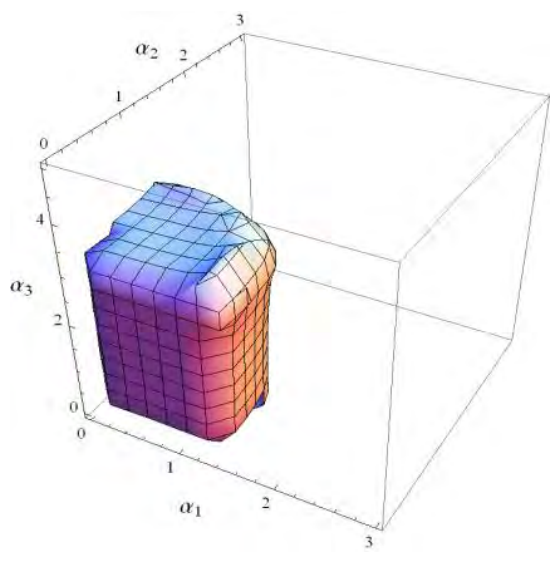

Figure 7: The stability region of the system when $\alpha_{4}=1, d=0.6, f_{1}=0.6, g=0.2$.

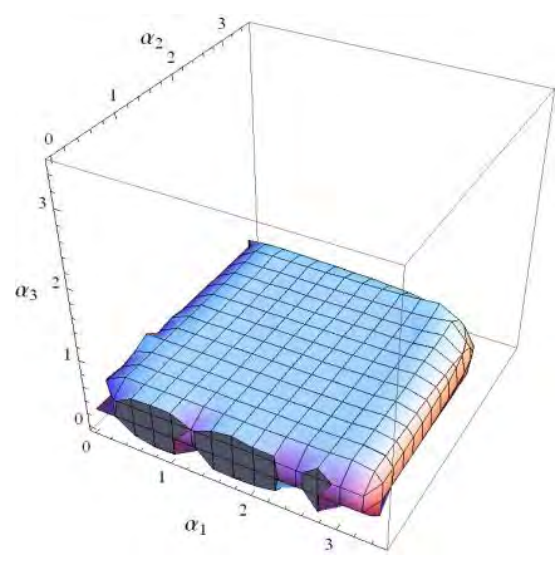

Figure 9: The stability region of the system when $\alpha_{4}=1, d=0.2, f_{1}=0.2, g=0.6$. 
Figs. 8 and 9 are the stable region of the system with $f_{1}=0.6$ and $g=0.6$ respectively, it can be seen that the stability region of output adjustment of the main manufacturer increases while the stability region of price adjustment of the complementary enterprise decreases. When $d$ and $g$ increase, the volume of stability region of Nash equilibrium point get smaller, which reduces the stable possibility of the system and increases the occurrence of disorderly market. So, decision makers should control adjustment speed in stability region to reduce the occurrence of disorderly market.

\subsection{The influence of adjustment speed on the stability of the system}

Fig. 10 shows the stability and instability regions of Nash equilibrium point of the system in the $\left(\alpha_{2}, \alpha_{3}\right)$ parameters plan when $e_{1}=f_{1}=0.6, \alpha_{1}=1, \alpha_{4}=1$. From the figure, we can find that if adjustment speed is too high, it will make the Nash equilibrium point lose stability. We can also find that the adjustment speed of price is more sensitive than the speed of output, when about $\alpha_{2}>2.05$, the Nash equilibrium pint will lose stability, while about $\alpha_{3}>1.12$ the Nash equilibrium point will do that, and price war is easier to get market into chaos.

Next, we will present the complex behaviours of the system. Fig. 11 presents the bifurcation diagram of the system with the change of $\alpha_{2}$ when $\alpha_{1}=1, \alpha_{3}=0.5, \alpha_{4}=1$ and $e_{1}=f_{1}=0.6$. Fig. 12 presents the bifurcation diagram of the system with the change of $\alpha_{3}$ when $\alpha_{1}=1, \alpha_{2}=1, \alpha_{4}=1$ and $e_{1}=f_{1}=0.6$. From Figs. 11 and 12, we can obtain that in Fig. 10, along the direction of arrow 2 and 3, the system loses its stability through flip bifurcation (called period-doubling bifurcation in continuous system). Fig. 13 presents the bifurcation diagram of the system with the change of $\alpha_{2}$ when $\alpha_{1}=1, \alpha_{3}=1, \alpha_{4}=1$ and $e_{1}=f_{1}=0.6$. Fig. 14 presents the bifurcation diagram of the system with the change of $\alpha_{3}$ when $\alpha_{1}=1, \alpha_{2}=1.7$, $\alpha_{4}=1$ and $e_{1}=f_{1}=0.6$. From Figs. 13 and 14, we can obtain that in Fig. 10, along the direction of arrow 1, the system first enters chaos through Neimark-Sacker bifurcation (called Hopf bifurcation in continuous system), then evolves into chaos through flip bifurcation separately.

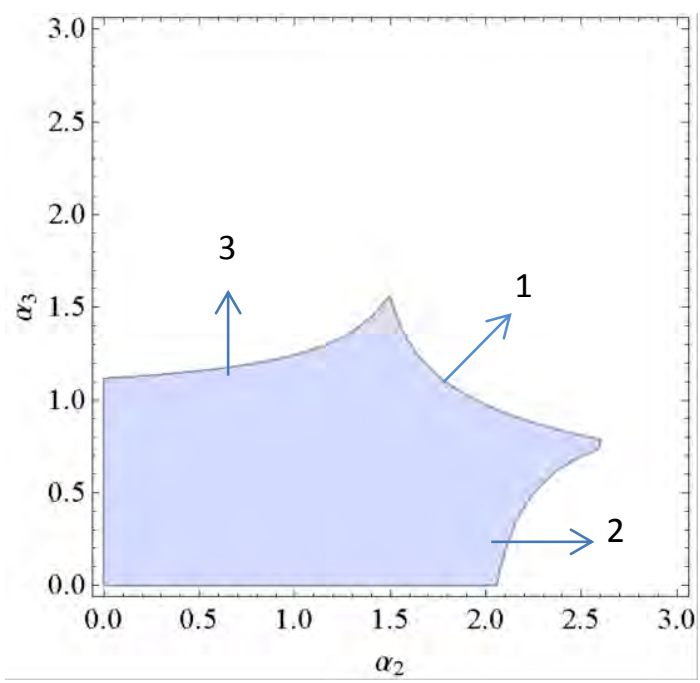

Figure 10: The stability region of the Nash equilibrium point of the system (when $e_{1}=f_{1}=0.6$ and $\alpha_{1}=1, \alpha_{4}=1$ ).

From the perspective of economics, the variable adjustment speed of enterprises should be in a certain range, otherwise, the system will come forth the cycle fluctuation, and then into chaos, which means irregular, sensitive to initial values, unpredictable and bad for the economy. 


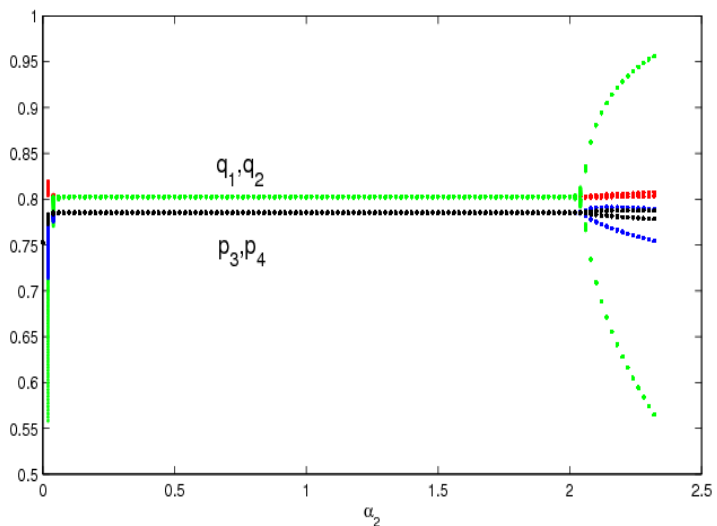

Figure 11: Track of $q_{1}, q_{2}, p_{3}, p_{4}$ with the change of $\alpha_{2}$ for $\alpha_{1}=1, \alpha_{3}=0.5$, $\alpha_{4}=1, e_{1}=f_{1}=0.6$.

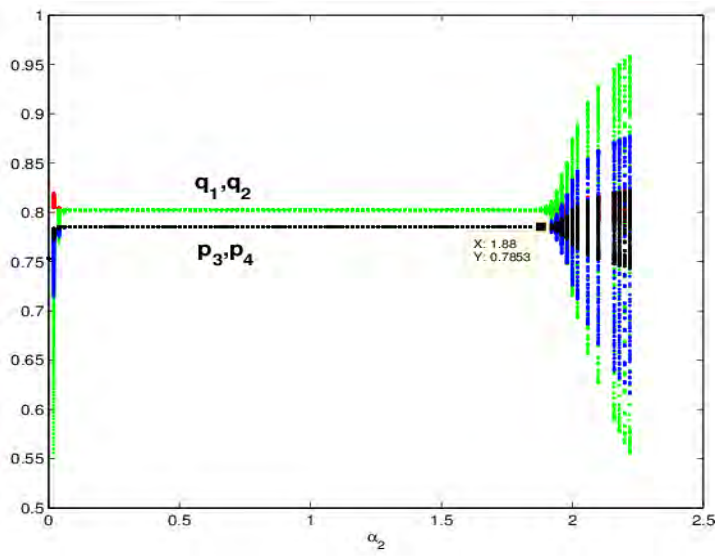

Figure 13: Track of $q_{1}, q_{2}, p_{3}, p_{4}$ with the change of $\alpha_{2}$ for $\alpha_{1}=1, \alpha_{3}=1$, $\alpha_{4}=1, e_{1}=f_{1}=0.6$.

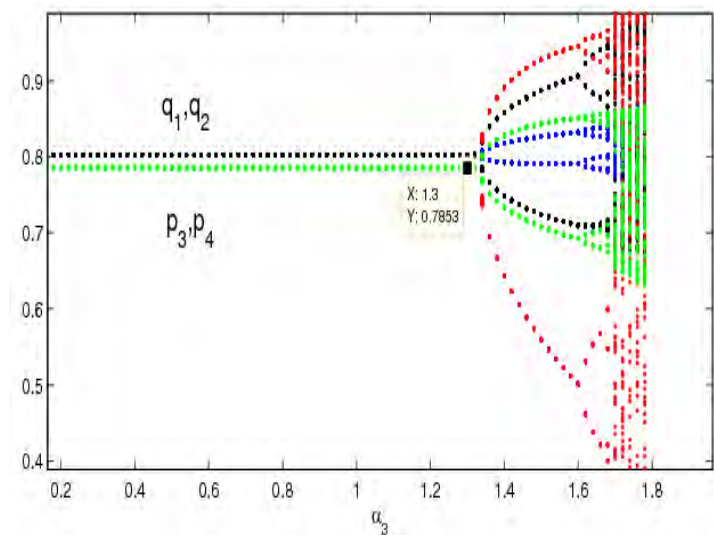

Figure 12: Track of $q_{1}, q_{2}, p_{3}, p_{4}$ with the change of $\alpha_{3}$ for $\alpha_{1}=1, \alpha_{2}=1$, $\alpha_{4}=1, e_{1}=f_{1}=0.6$.

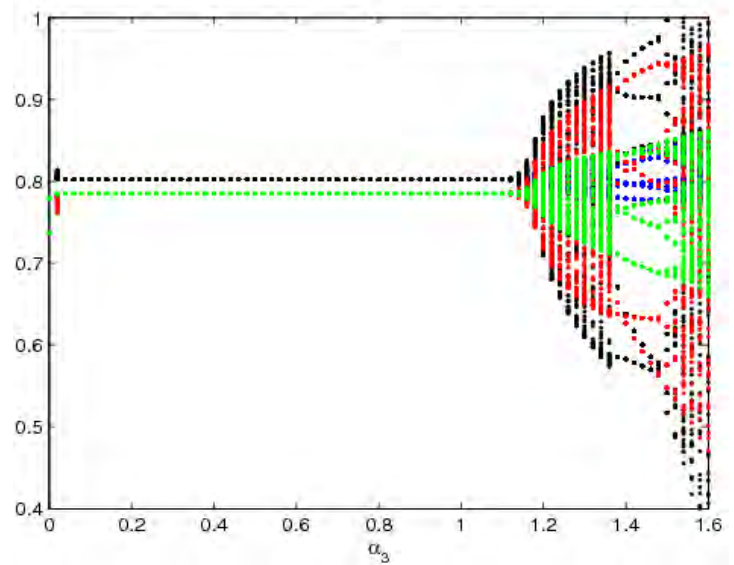

Figure 14: Track of $q_{1}, q_{2}, p_{3}, p_{4}$ with the change of $\alpha_{3}$ for $\alpha_{1}=1, \alpha_{2}=1.7$, $\alpha_{4}=1, e_{1}=f_{1}=0.6$.

\section{THE SIMULATION BASED ON THE CHAOS CONTROL}

Through the above analysis, we can see that if adjustment speed of variables is too large, it can make the system enter into a chaos state which is very bad for enterprises. However, the current situation is that the enterprises often take all kinds of means for their purpose of profit maximization, and often cause market disorder which adversely affect each part in the market and will simultaneously do a great deal of harm to the whole economic operation. It is particularly important for each enterprise to adopt control measures timely to make the system turn to the stability state again. Based on the above analysis, the parameter adjustment and feedback control method will be used to control the chaos of the system, which is often used in general discrete dynamic system. We will analyse chaos control based on the influence of control parameter $(\mu)$ on the stability of the system.

Assume the system is:

$$
\begin{array}{ll}
q_{i}(t+1)=f_{i}\left(q_{1}(t), q_{2}(t), p_{3}(t), p_{3}(t)\right), & i=1,2 \\
p_{j}(t+1)=f_{j}\left(q_{1}(t), q_{2}(t), p_{3}(t), p_{3}(t)\right), & j=3,4
\end{array}
$$

The model under control is as follows: 


$$
\begin{aligned}
& q_{1}(t+m)=(1-\mu) f_{1}^{m}\left(q_{1}(t), q_{2}(t), p_{3}(t), p_{3}(t)\right)+\mu q_{1}(t) \\
& q_{2}(t+m)=(1-\mu) f_{2}^{m}\left(q_{1}(t), q_{2}(t), p_{3}(t), p_{3}(t)\right)+\mu q_{2}(t) \\
& p_{3}(t+m)=(1-\mu) f_{3}^{m}\left(q_{1}(t), q_{2}(t), p_{3}(t), p_{3}(t)\right)+\mu p_{3}(t) \\
& p_{4}(t+m)=(1-\mu) f_{4}^{m}\left(q_{1}(t), q_{2}(t), p_{3}(t), p_{3}(t)\right)+\mu p_{4}(t)
\end{aligned}
$$

When $\mu=0$, the model (10) is the original system (model 5), thus, the controlled model (10) has the same periodic orbit with the system. When $m=1$, each step iteration of the Nash equilibrium point is in control. When $m=2$, 4, etc., namely to control the second cycle orbit, four cycles orbit. In this paper, we discuss the stability control of model (6) when $m=1$.

Using the same market parameters as before, solve the controlled system (10); then we know that the value of the only Nash equilibrium is the same as system (5).

Obviously, when $\mu \neq 0$, the value of $\mu$ has influence on the eigenvalues of the equilibrium's Jacobian matrix of the controlled system (10), so $\mu$ will affect the stable region of the Nash equilibrium of the controlled system (10).

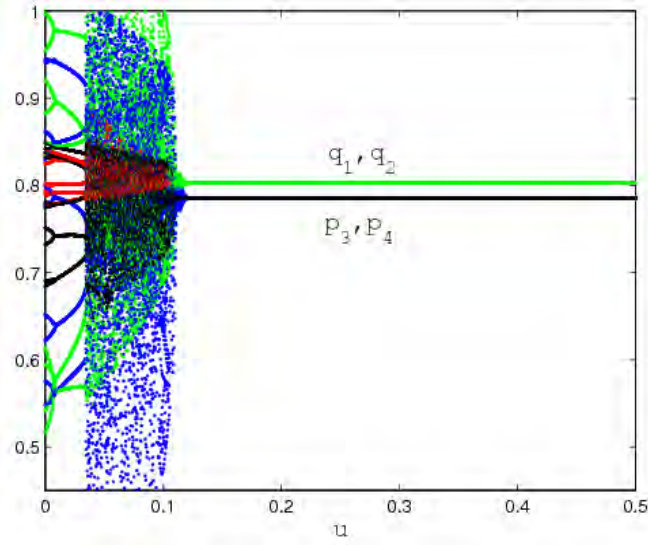

Figure 15: Chaos control with parameter $\mu$ when $\alpha_{1}=1, \alpha_{2}=1.7, \alpha_{3}=1.5$, $\alpha_{4}=1$ and $e_{1}=f_{1}=0.6$.

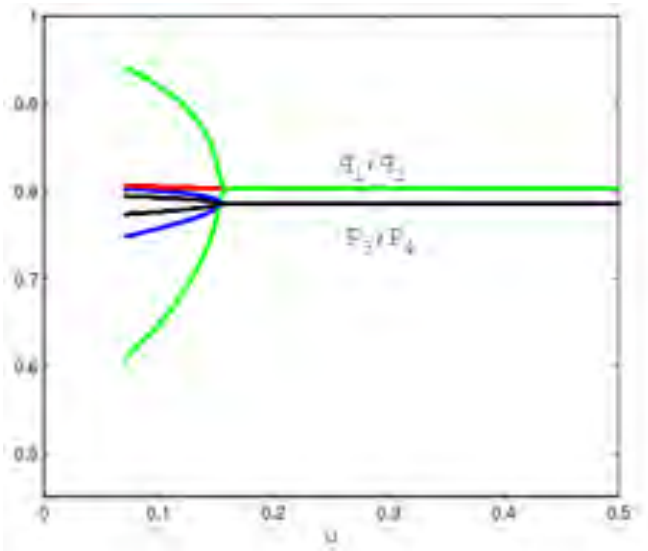

Figure 16: Chaos control with parameter $\mu$ when $\alpha_{1}=1, \alpha_{2}=1.7, \alpha_{3}=0.5$, $\alpha_{4}=1$ and $e_{1}=f_{1}=0.6$.

From Fig. 15, when $\alpha_{1}=1, \alpha_{2}=1.7, \alpha_{3}=1.5, \alpha_{4}=1$ and $e_{1}=f_{1}=0.6$, the model (10) changes from flip bifurcation, Neimark-Sacker bifurcation to stability state at $\mu=0.12$. From Fig. 16, we can see that, when $\alpha_{1}=1, \alpha_{2}=1.7, \alpha_{3}=0.5, \alpha_{4}=1$ and $e_{1}=f_{1}=0.6$, the model (10) tends to be stable at $\mu=0.16$ with the changes of $\mu$.

\section{CONCLUSIONS}

In this article, we mainly construct the Cournot-Bertrand game models and study its dynamic characteristic using numerical simulation. The two main manufacturers produce two differentiated products and two complementary enterprises offer two complements. According to the simulation of the model, we can obtain the influence of complementarity and substitutability on system variables and profit, when the variable adjustment is too large, the system will present complex dynamic behaviours, namely, chaos. The stability region of output adjustment becomes smaller and the stability region of price adjustment becomes larger with substitutability of main manufacturers increasing. The stable region of output adjustment becomes larger and the stable region of price adjustment becomes smaller with complementarity and the substitutability of complementary enterprises increasing. These results can provide references for decision makers in product design, the choice of complementary product strategy and variable adjustment. 


\section{ACKNOWLEDGEMENTS}

The authors would like to thank the reviewers for their careful reading and some pertinent suggestions. The research was supported by the National Natural Science Foundation of China (No. 70971095), the Ministry of Science and Technology Foundation of China (No. 2012IM040500) and the doctoral scientific Fund Project of the Ministry of Education of China (No. 20120032110035).

\section{REFERENCES}

[1] Lu, J.-C.; Tsao, Y.-C.; Charoensiriwath, C. (2011). Competition under manufacturer service and retail price, Economic Modelling, Vol. 28, No. 3, 1256-1264, doi:10.1016/j.econmod.2011.01.008

[2] Wang, S.-D.; Zhou, Y.-W.; Min, J.; Zhong, Y.-G. (2011). Coordination of cooperative advertising models in a one-manufacturer two-retailer supply chain system, Computers \& Industrial Engineering, Vol. 61, No. 4, 1053-1071, doi:10.1016/j.cie.2011.06.020

[3] Gal-Or, E. (1985). Information sharing in oligopoly, Econometrica, Vol. 53, No. 2, 329-343, doi: $10.2307 / 1911239$

[4] Vives, X. (1984). Duopoly information equilibrium: Cournot and Bertrand, Journal of Economic Theory, Vol. 34, No. 1, 71-94, doi:10.1016/0022-0531(84)90162-5

[5] Cai, G.; Zhang, Z. G.; Zhang, M. (2009). Game theoretical perspectives on dual-channel supply chain competition with price discounts and pricing schemes, International Journal of Production Economics, Vol. 117, No. 1, 80-96, doi:10.1016/j.ijpe.2008.08.053

[6] Cao, P.; Li, J.; Yan, H. (2012). Optimal dynamic pricing of inventories with stochastic demand and discounted criterion, European Journal of Operational Research, Vol. 217, No. 3, 580-588, doi:10.1016/j.ejor.2011.09.048

[7] Kuo, C.-W.; Huang, K.-L. (2012). Dynamic pricing of limited inventories for multi-generation products, European Journal of Operational Research, Vol. 217, No. 2, 394-403, doi:10.1016/j.ejor.2011.09.020

[8] Xia, Y. (2011). Competitive strategies and market segmentation for suppliers with substitutable products, European Journal of Operational Research, Vol. 210, No. 2, 194-203, doi:10.1016/j.ejor.2010.09.028

[9] Soon, W. (2011). A review of multi-product pricing models, Applied Mathematics and Computation, Vol. 217, No. 21, 8149-8165, doi:10.1016/j.amc.2011.03.042

[10] Yue, X.; Mukhopadhyay, S. K.; Zhu, X. (2006). A Bertrand model of pricing of complementary goods under information asymmetry, Journal of Business Research, Vol. 59, No. 10-11, 1182-1192, doi:10.1016/j.jbusres.2005.06.005

[11] Mukhopadhyay, S. K.; Yue, X.; Zhu, X. (2011). A Stackelberg model of pricing of complementary goods under information asymmetry, International Journal of Production Economics, Vol. 134, No. 2, 424-433, doi:10.1016/j.ijpe.2009.11.015

[12] Lewis, J. D. (1999). Trusted partners: How companies build mutual trust and win together, Free Press, New York

[13] Cournot, A. (1927). Researches into the mathematical principles of the Theory of wealth, Bacon, N. T. (Translation), Macmillan: New York

[14] Economides, N. (1996). Network externalities, complementarities and invitations to enter, European Journal of Political Economy, Vol. 12, No. 2, 211-233, doi:10.1016/0176-2680(95)00014-3

[15] Yan, R.; Bandyopadhyay, S. (2011). The profit benefits of bundle pricing of complementary products, Journal of Retailing and Consumer Services, Vol. 18, No. 4, 355-361, doi:10.1016/j.jretconser.2011.04.001

[16] Yan, R.; Myers, C.; Wang, J.; Ghose, S. (2014). Bundling products to success: The influence of complementarity and advertising, Journal of Retailing and Consumer Services, Vol. 21, No. 1, 48-53, doi:10.1016/j.jretconser.2013.07.007 
[17] Shelegia. S. (2012). Multiproduct pricing in oligopoly, International Journal of Industrial Organization, Vol. 30, No. 2, 231-242, doi:10.1016/j.ijindorg.2011.10.001

[18] Naimzada, A. K.; Tramontana, F. (2012). Dynamic properties of a Cournot-Bertrand duopoly game with differentiated products, Economic Modelling, Vol. 29, No. 4, 1436-1439, doi:10.1016/j.econmod.2012.02.016

[19] Bylka, S.; Komar, J. (1976). Cournot-Bertrand mixed oligopolies, Beckmann, M.; Kunzi, H.-P. (Eds.), Lecture Notes in Economics and Mathematical Systems, Vol. 133, 22-33, Springer, New York

[20] Singh, N.; Vives, X. (1984). Price and quantity competition in a differentiated duopoly, The RAND Journal of Economics, Vol. 15, No. 4, 546-554

[21] Hackner, J. (2000). A note on price and quantity competition in differentiated oligopolies, Journal of Economic Theory, Vol. 93, No. 2, 233-239, doi:10.1006/jeth.2000.2654

[22] Zanchettin, P. (2006). Differentiated duopoly with asymmetric costs, Journal of Economics \& Management Strategy, Vol. 15, No. 4, 999-1015, doi:10.1111/j.1530-9134.2006.00125.x

[23] Arya, A.; Mittendorf, B.; Sappington, D. E. M. (2008). Outsourcing, vertical integration, and price vs. quantity competition, International Journal of Industrial Organization, Vol. 26, No. 1, 1-16, doi:10.1016/j.ijindorg.2006.10.006

[24] Ma, J.; Li, Q. (2014). The complex dynamics of Bertrand-Stackelberg pricing models in a risk-averse supply chain, Discrete Dynamics in Nature and Society, Vol. 2014, Article ID 749769, 14 pages, doi: $10.1155 / 2014 / 749769$

[25] Gabszewicz, J.; Sonnac, N.; Wauthy, X. (2001). On price competition with complementary goods, Economics Letters, Vol. 70, No. 3, 431-437, doi:10.1016/S0165-1765(00)00383-9

[26] Wei, J.; Zhao, J.; Li, Y. (2013). Pricing decisions for complementary products with firms' different market powers, European Journal of Operational Research, Vol. 224, No. 3, 507-519, doi:10.1016/j.ejor.2012.09.011

[27] Fanti, L.; Gori, L.; Mammana, C.; Michetti, E. (2013). The dynamics of a Bertrand duopoly with differentiated products: Synchronization, intermittency and global dynamics, Chaos, Solitons \& Fractals, Vol. 52, 73-86, doi:10.1016/j.chaos.2013.04.002

[28] Puu, T. (2003). Attractors, bifurcations, and chaos: Nonlinear phenomena in economics, Springer, New York 